\title{
ROAD TO MYTHIC: CONCEPTUALIZATION OF INTERNET GAMING FROM THE LIVED EXPERIENCES OF SYMPTOMATIC FILIPINO YOUTH
} Marris R. Reyes ${ }^{*}$, Arnulfo V. Lopez ${ }^{2}$

${ }^{1 *}$ The Graduate School, University of Santo Tomas, España, Manila, Philippines, and Extension and Training Director, Isabela State University - Jones Campus, Jones, Isabela Philippines; ${ }^{2}$ The Graduate School, University of Santo Tomas, España, Manila, Philippines.

Email: *marris.r.reyes@isu.edu.ph

Article History: Received on $20^{\text {th }}$ April 2020, Revised on $25^{\text {th }}$ June 2020, Published on $17^{\text {th }}$ July 2020

\section{Abstract}

Purpose of the study: The purpose of this study is to capture the lived experiences of Filipino College Students excessively immersed in online gaming for a year or more with five or more symptoms of Internet Gaming Disorder (I.G.D.).

Methodology: This is a qualitative research using the phenomenological approach. Internet Gaming Disorder Scale Short form (IGD9-SF) was used to identify participants. Using Paul Colaizzi's Procedure, field text was carefully transcribed and analyzed to determine the statement verbalizations and musings, which collectively described the phenomenon.

Main Findings: The conceptual model "E-Loop of I.G.D.” or the "Entertain-Engulfed-Entangle-Escape” has emerged. The findings of this study established the severity of the adverse effects of I.G.D. To students and the severe gaming dysregulation, this resulted in a vacuum in their personal development.

Applications of this study: This model provided a clear picture of a vicious cycle of dysregulated internet gaming behaviour which would equip mental health experts' richer understanding and analysis of action related to gaming. Ultimately, this inference offers an appropriate basis for intervention or treatment programs in assisting students with I.G.D. symptoms.

Novelty/Originality of this study: This study provided a novel conceptual framework of internet gaming disorder based on the lived experiences of the symptomatic gamers. Further, it offered more definite conceptions on the vicious cycle of I.G.D.

Keywords: Internet Gaming, Internet Gaming Disorder, Phenomenology, E-Loop of I.G.D., Lived Experiences, Symptomatic.

\section{INTRODUCTION}

Collegiate years prepare students to become globally competitive and successful professionals. Also, this is the time when they experience challenges and distractions that can be disadvantageous to their growth. Just like these two students; one who has been a consistent honour student and the other was a regular gold medallist in sports competition. The first one displayed a dramatic decline in academic performance, and the other one got kicked-out from the varsity team. These were due to persistent tardiness and absences during class/training, and being inattentive in classes/training. After a series of inquiries and observations, it was found that there were neither familial nor financial problems, but these students were "passionately" engaged in online gaming.

Across the lifespan, gaming had been part of humanity (Rahmadi \& Prambayun, 2019) and has been essential, beneficial and regular activity (Koshleva et al., 2020). Games can improve children's mental processing (Rosyati et al., 2020) and can hone skills of individuals in different facets such as psychological, social, and cultural (King \& Delfabbro, 2019). Though in general, it is perceived to be advantageous, the continuously growing trend to online gaming over the previous decade has given birth to problematic gaming. Since the rise of the internet age has paved the way for constant technological expansion and limitless potentials, it is hugely advantageous to education systems (Kamenez, 2020), online marketing (Suriya, 2019), communication (Kosheleva et al., 2020), among others. Yet, behind the advancement, it conveys, lays huge detriments especially to the mental health of its users. The exciting features of the internet overwhelmed human beings to the extent of overlooking their physical and psychosocial needs. Engaging in online gaming have become the priority leisure activities of children and the young generation (King \& Delfabbro, 2019). While some of them use gaming in a regulated and healthy way, most students displayed a dramatic decline in physical hygiene, academic and curricular activities, hindrances good interpersonal relationships among significant others and the society as a whole.

The excessive use of the internet gained attention at the dawn of the $21^{\text {st }}$ century in the face of Internet Addiction Disorder (IAD) (Király, Griffiths \& Demetrovics, 2015). As early as 2001, the American Psychological Association (A.P.A.) emphasized that the meteoric growth in internet access had brought with it broad problematic internet behaviours (Cash et al., 2012). Since then, innovation and studies were conducted to minimize the condition. However, the problem ceaselessly exists and continually evolved. Currently, "internet gaming disorder" has been the focus of researchers due to its severe adverse effects on the physical, sociological and psychological well-being of the youth, 
especially among students. It has been recognized as a global concern since it is resulting in the harmful impacts on different facets of individual growth mostly of adolescents and young adults. It is there increasing recognition of harmful impacts related to time spent in gaming, particularly among the younger population (King \& Delfabbro, 2019). I.G.D. is characterized by "persistent gaming and functional impairment in multiple areas of life" (King \& Delfabbro, 2019). Recently, the A.P.A. identified I.G.D. in Section 3 of the Diagnostic and Statistical Manual $5^{\text {th }}$ Edition (DSM-5) as a condition worthy of future study towards its possible inclusion to the main lists mental disorder (King \& Delfabbro, 2019; Kuss et al., 2017). Furthermore, the World Health Organization (WHO, 2018) included video gaming addiction as a mental illness under addictive behaviours in the list of psychological, behavioural or neurodevelopmental disorders of International Codes of Diagnosis - 11. Since then, researchers focused on its conceptualization, risk factors and treatment protocols. Yet, the condition has been under confusions and debates among academicians, mental health practitioners and researchers. Feng, Ramo, Chan and Burgeois (2017) explained that research publications in gaming and internet addiction had increased rapidly in the last decades. Yet, there is still a need for in-depth analysis to understand the disorder.

Understanding and explaining the phenomenon requires further first-hand inquiries. Captivated by the opening story of college students and the importance of gaming in human lives, this research sought to investigate the underlying factors and concepts of the condition by answering the central question: "How do symptomatic Filipino college students perceive and experience internet gaming disorder symptoms?" Beholding from the lens of the gamers, this inquiry will fill-in the gaps in understanding and conceptualizing the I.G.D. Findings of this study will contribute to the existing literature on Internet Gaming Disorder as well as provide valuable knowledge and insights that probe on the dynamic social experiences and relational interactions of Filipino College students with I.G.D. symptoms. Specifically, the emerged themes of internet gaming disorder will serve as a guide towards the formulation of proper intervention programs to manage/control the symptoms. Thru phenomenology, various personas of students excessively engaged in gaming will offer an exciting map towards understanding and conceptualizing unknown features of I.G.D.

\section{LITERATURE REVIEW}

Online gamings gained its popularity and have been a vital part of entertainment and leisure activities in households around the world (Pontes, 2016). As reported by the Entertainment Software Association-ESA (2017), "67\% of the American household own a video gaming device used to play games". Reports also revealed that China has 257 million video gamers (Snyder, 2018). In 2015, it was reported by Petry et al. that based on the criteria from the DSM-5 the global prevalence of I.G.D. ranges from $0.5 \%$ to $6 \%$ (as cited from In the Philippines, the statistics on video gaming (online/offline) has not been well established even the fondness of Filipinos in online gaming is visibly seen in the streets, inside the classrooms and outside schools with internet cafes. With its users around the globe, questions to whether it should be considered a psychiatric/psychological condition was raised, making it controversial.

Though researchers have been successful in proving the positive effects of video gaming to individuals such as enhanced cognitive abilities (Gee, 2003), interpersonal effects to a person with autism (Gallup et al., 2016), hand-eye motor coordination, its adverse effects to most gamers should be given attention. American Psychiatric Association (2013) stated that "gamers play compulsively, to the exclusion of other interests, and their persistent and recurrent online activity results in clinically significant impairment or distress". Additionally, A.P.A. (2013) stated that the gamers' brain activity when gaming triggers "neurological response" affecting the feeling of "reward and pleasure" which is similar to those with substance-abuse disorders. Research also found that games may include illicit "aggression, addiction, depression, anxiety and obsessive-compulsive disorder" (Pontes et al., 2019). Further, theoretical, empirical, and clinical evidence had proven that I.G.D. exists.

One of the significant barriers of psychological inquiry of I.G.D. is its lack of clear definition and conceptualization. Numerous studies explained I.G.D. as a complicated case of addiction based on previous theories explaining behavioural addiction. It has been in the middle of debates, and continuous conceptualization since psychological inquiries in this field started (Pontes, 2016). Mills and Allen (2019) characterized I.G.D. as a "sustained, problematic pattern of video gaming which contributed to both physical and psychological harms". Kardefelt-Winther et al. (2017) characterized behavioural problem such as I.G.D. with recurrent individual's actions which can result in a harmful or distressful situation which is persistent over a significant period in which the damage is functionally impairing in nature. This explanation is generally applicable to other behavioural addiction including gambling and gaming (Kardefelt-Winther et $\underline{\mathrm{al}, 2017)}$ and not exclusively characterizing the specific and unique condition of I.G.D. As discussed by Volkow and Li, and Nestler pleasurable aspects of behaviour such as taking prohibited drugs will access the reward circuits of the brain which was similar to the brain activity of online gamers (as cited in Dong \& Pontenza, 2015). Motivation-focused models suggested that addiction rooted from errors in motivation wherein relatively higher priority focused on behaviours such as drug use or gambling (Dong \& Ponteza, 2015) as cited from Chambers, et al). Furthermore, the Cognitive-Behavioural model has been utilized in explaining I.G.D. focused on reward circuits (Weinstein et al, 2017). A.P.A. (2013) proposed a clinical definition of I.G.D. as "persistent and recurrent use of the Internet to engage in gaming, often with other players, leading to clinically significant impairment or distress". I.G.D. is present if a gamer

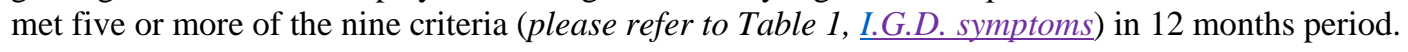


Though very similar to other behavioural addiction, internet gaming is a condition that allows gamers to engage in a virtual world, virtually escape reality which affects primarily their imagination and perception of the real world. Also, gaming is not collectively detrimental to all users (King \& Delfabbro, 2019). Unlike substance abuse, smoking and gambling, it is not inherently unhealthy activity and as mentioned gamers can warrant some benefits. Thus, considering this scientific assumption, its conceptualization and definition needs further empirical studies. Petry et al., (2014) claimed a conceptual outlining of I.G.D. constructs parallel to substance abuse disorder (S.A.D.) since gaming (G.D.) is inherently addictive. Moreover, as supported by the assumption of Belanger-Lejars (2015) that though I.G.D. and G.D. are distinct, both come together on individual psychological risk factors. As well, Saquib et al., (2017) who examined the contribution of mental distress to excessive video gaming concluded that more considerable difficulty leads to a higher risk of game addiction. However, these inferences are confronted by various researches (Kiraly et al., 2015), arguing that video gaming is a self-regulatory challenge. Scharkow et al. (2014) showed evidence those I.G.D. symptoms akin to social and mental health. Recent developments suggested hyperactivity and inattention and self-esteem problems were predictors of I.G.D. (Wartberg et al., 2018). Wartberg and his colleagues (2017) found that emotional distress and parental anxiety have strong effects on I.G.D. Further, Moudiab and Spada (2019) tested the "relative contribution of motives and maladaptive cognitions to levels of I.G.D." suggested a dominant triad of I.G.D. characterized by "being motivated to the game means coping in life; being motivated to hone gaming skills, and, overvaluing games' rewards". The recent literature suggested that I.G.D. had a pool of risk factors affecting the cognition, motivation, sensation, behaviour, interpersonal relations and even physical health of the gamers.

To date, conflicts with whether I.G.D. should be called a mental illness are still on-going. In an article by Bax (2016), he claimed that rather than a mental disorder, I.G.D. simply is a social deviance. He explained that more than a deterioration of mental health, it is merely a social problem which needs appropriate methods that require real-world solutions. A sharp criticism of its recognition as a behavioural addiction, the term "addiction" may suffer potential devaluation due to its permissive nature (Király et al., 2015). Moreover, Billieux et al. (2015) emphasized that researchers tended to over anthologize everyday life behaviours such as gaming. However, from the findings, I.G.D. could prospectively contribute to the deterioration of mental health (Wartberg et al., 2018). Belanger-Lejars (2015) argued that psychological risk factors of I.G.D. could lead to not only the decline of mental health and psychological well-being but the physical health of its gamers. Deleuze et al. (2018) also tried to distinguish "passion" and "addiction" of players. Results suggested high engagement and problematic gaming are distinct but were related (Deleuze et al., 2018). Hence, refinement of the diagnostic approach and conceptualization of I.G.D. were timely to avoid confusions with normal to problematic gaming. Various researchers have also linked I.G.D. to different psychological constructs.

With the enumerated characteristics, signs, and symptoms of this condition, it was seen that excessive internet gaming negatively affects the physical, mental, and sociological welfare of the gamers. Having the capability to predict, diagnose and manage I.G.D. symptoms play a vital role in its prevention. Hence, possible risk factors linked with I.G.D. requires thorough understanding. However, in the present day, the risk factors and causes are subject to further research and exploration. As stated by Feng et al. (2017) and Wartberg et al. (2018), research and conceptualization with I.G.D. is at its infancy and needs further psychological inquiry. Notwithstanding the growing studies regarding the epidemiology of internet gaming disorder (I.G.D.), influencing factors examined to a lesser extent, such as psychological needs and self-control. Thus, to give light to grey areas on conceptualization, the present study will determine the concepts of the phenomenon with insiders' perspectives and experiences of the gamers themselves with in-depth individual conversations.

\section{RESEARCH METHODS}

A substantial consideration with regards to the use of a qualitative approach in this paper is its ability to fully define and understand the phenomenon using the lived experiences of the gamers. As cited by de Guzman and Hapan (2013), "for people to understand better, they should be provided with information in the form which they usually experience" (cited from Lincoln \& Guba, 1985). The researcher carefully recorded, describe, and understand the lived experiences and reality of the Filipino college students with symptoms of I.G.D., using descriptive phenomenology. Husserl (1970 as cited in de Guzman \& Hapan, 2013), defined phenomenology as "the science of the essence of consciousness, focused on defining the concept of intentionality, and meaning of lived experiences from the first-person point of view".

Data from participants were gathered as a part of a more extensive pilot study assessing college students with I.G.D. symptoms. In-depth interviews with 37 participants with five or more symptoms for a year or more were conducted. Utilizing the science of essences, this phenomenological research intended to characterize the experiences in the original context of college students (A.Y. 2019-2020) with internet gaming disorder symptoms. Participants were selected using the Internet Gaming Disorder Scale - Short Form (IGDS9-SF). IGDS9-SF is a short psychometric tool which is based on the given criteria in the DSM-5 (Pontes et al., 2019). This tool is widely used by researchers to identify and observe the severity of I.G.D., which is present for a year or more (Pontes \& Griffiths, 2015; Lemmens et al., 2015). The sample size in this qualitative method depends on what should be known, its purpose, its benefits and things to be done with the available resources within a period (Patton, as cited in Castro \& de Guzman, 2012). Creswell (1998) stated that phenomenological research involves in-depth interviews with only three to thirteen selections (as cited in Castro \& de Guzman, 2012). Participants shared his/her gaming experiences in an in-depth interview. The inclusion criteria were as 
follows: male/female college students; from 18 to 25 years' old who actively plays internet games for over 12 months; with five or more symptoms using IGDS9-SF. Participants have been active in the virtual environment such as massively multiplayer online role-playing games (MMORPGs), and multiplayer online battle arena (MOBA) for more than a year. Of the selection, $8(21.62 \%)$ were females and $29(78.38 \%)$ were males. The majority or $62.16 \%$ of the participants' onset of gaming is during high school. Most of the participants spent four to eight hours in gaming (48.65\%), 29.73\% spent eight to sixteen hours while $21.62 \%$ spent one to four hours in gaming. All participant gamers are using mobile devices and personal computers for gaming.

Table 1: Profile of the Participants

\begin{tabular}{|c|c|c|c|c|c|}
\hline Profile & Frequency & $\begin{array}{l}\text { Percent } \\
\text { age }(\%)\end{array}$ & I.G.D. Symptoms & Frequency & $\begin{array}{l}\text { Percentage } \\
(\%)\end{array}$ \\
\hline Age & & & 1. preoccupation with internet games & 37 & 100 \\
\hline $18-21$ & 32 & 86.49 & 2. withdrawal symptoms & 29 & 78.38 \\
\hline $22-25$ & 5 & 13.51 & 3. tolerance & 37 & 100 \\
\hline Gender & & & $\begin{array}{c}\text { 4. unsuccessful attempts to control } \\
\text { gaming }\end{array}$ & 37 & 100 \\
\hline Male & 29 & 78.38 & $\begin{array}{l}\text { 5. loss of interest in previous hobbies and } \\
\text { entertainment }\end{array}$ & 34 & 91.89 \\
\hline Female & 8 & 21.62 & 6. continued excessive internet game use & 34 & 91.89 \\
\hline $\begin{array}{l}\text { Onset of } \\
\text { Gaming }\end{array}$ & & & $\begin{array}{l}\begin{array}{l}\text { despite } \\
\text { awareness } \\
\text { problems }\end{array} \text { of } \quad \text { psychosocial } \\
\end{array}$ & & \\
\hline $\begin{array}{l}\text { Element } \\
\text { ary }\end{array}$ & 13 & 35.14 & $\begin{array}{c}\text { 7. deception of others regarding the } \\
\text { amount of gaming }\end{array}$ & 29 & 78.38 \\
\hline $\begin{array}{l}\text { High } \\
\text { School }\end{array}$ & 23 & 62.16 & $\begin{array}{l}\text { 8. use of internet games to escape or } \\
\text { relieve negative }\end{array}$ & 27 & 72.97 \\
\hline College & 1 & 2.70 & moods & & \\
\hline $\begin{array}{l}\text { Time Spent in } \\
\text { Gaming }\end{array}$ & & & $\begin{array}{l}\text { 9. loss of significant relationships, jobs, } \\
\text { or other }\end{array}$ & 37 & 100 \\
\hline $\begin{array}{l}1-4 \\
\text { hours }\end{array}$ & 8 & 21.62 & $\begin{array}{l}\text { opportunities because of internet } \\
\text { gaming }\end{array}$ & & \\
\hline $\begin{array}{l}4-8 \\
\text { hours }\end{array}$ & 18 & 48.65 & & & \\
\hline $\begin{array}{l}8-16 \\
\text { hours }\end{array}$ & 11 & 29.73 & & & \\
\hline \multicolumn{6}{|l|}{$\begin{array}{l}\text { Gaming } \\
\text { Devices Used }\end{array}$} \\
\hline $\begin{array}{l}\text { Mobile } \\
\text { Devices }\end{array}$ & 37 & 100.00 & & & \\
\hline Console & 1 & 2.70 & & & \\
\hline $\begin{array}{l}\text { Comput } \\
\text { ers }\end{array}$ & 37 & 100.00 & & & \\
\hline
\end{tabular}

Capturing the essence of the phenomenon, the researcher sent a letter of invitation and informed consent form (which indicates relevant information of the study, issue to converse, and extent of the participation) to the purposively selected college students at Isabela State University. After obtaining their consent, the researcher's scheduled appointment for one-on-one interviews based on their availability and convenience. First, the participants were requested to accomplish a "robotfoto" (Kelchtermans \& Ballet, as cited in de Guzman \& Hapan, 2013) that provided their preliminary information. The in-depth, semi-structured interview using the Filipino language, mainly focused on their preoccupation, gaming behaviours and psychosocial experiences with excessive video gaming. The sharing and reflections of the conversations focused on the following key questions in the interview guide: (a) how often you play online games? How would you describe your reactions, thoughts and feelings while gaming? (b) How is your relationship with your family, friends and other significant people in your life before and after excessive gaming? (c) How does gaming become a dominant activity that affects your daily life? (d) What are the benefits you receive from internet gaming? Interview questions were open-ended, and the flow of discussion was determined by the participants. However, in some instances, the researcher needed to clarify and probe deeper into specific responses thru follow-up questions. The researcher asked the permission of the participants to record the conversations. This is to facilitate the transcription and data analysis. The researcher manually transcribed the audio-recorded interviews.

Paul Colaizzi's Procedure was utilized to gain the essence of the phenomenon (internet gaming disorder) under inquiry (Morrow, Rodgriguez, \& King, 2015). The data gathered were carefully read and re-read to excerpt and extract significant expressions that collectively described what was common among the participants' perception and 
experiences. Vital phrases and statements were reduced to categorized codes and themes to create a bright and holistic presentation of their experiences. Moreover, chosen expressions and verbalizations of the participants were carefully translated to the English language to facilitate understanding of non-Filipino readers. To facilitate the cold and warm analyses of gathered text, the researcher used the repertory grid to reveal an eidetic central meaning of the experience. Themes that emerged were characterized as truthfully and as accurately as possible. The researcher utilized the critical friend technique and correspondence technique to guarantee the trustworthiness and truthfulness of the gathered data (Morrow et al., 2015).

\section{RESULTS/FINDINGS}

Findings of this qualitative inquiry clearly and holistically characterized the lived experiences of college students with internet gaming disorder symptoms as they experience physical and psychosocial difficulties. The richness and thickness of the field texts gathered identified four rotating patterns of the Entertain-Engulfed-Entangle-Escape or the "E-loop of Internet Gaming Disorder" (Figure 1). The dynamics of these series of model explained the excessive and unstoppable online gaming cycle of the young generation. Although the emerged trends simultaneously developed in different settings, I.G.D. symptoms represent separate phenomena which commenced one after another, as a response to their increased urge to online gaming and the growing pressure they felt brought about by systems of their respective games, then go back to the beginning.

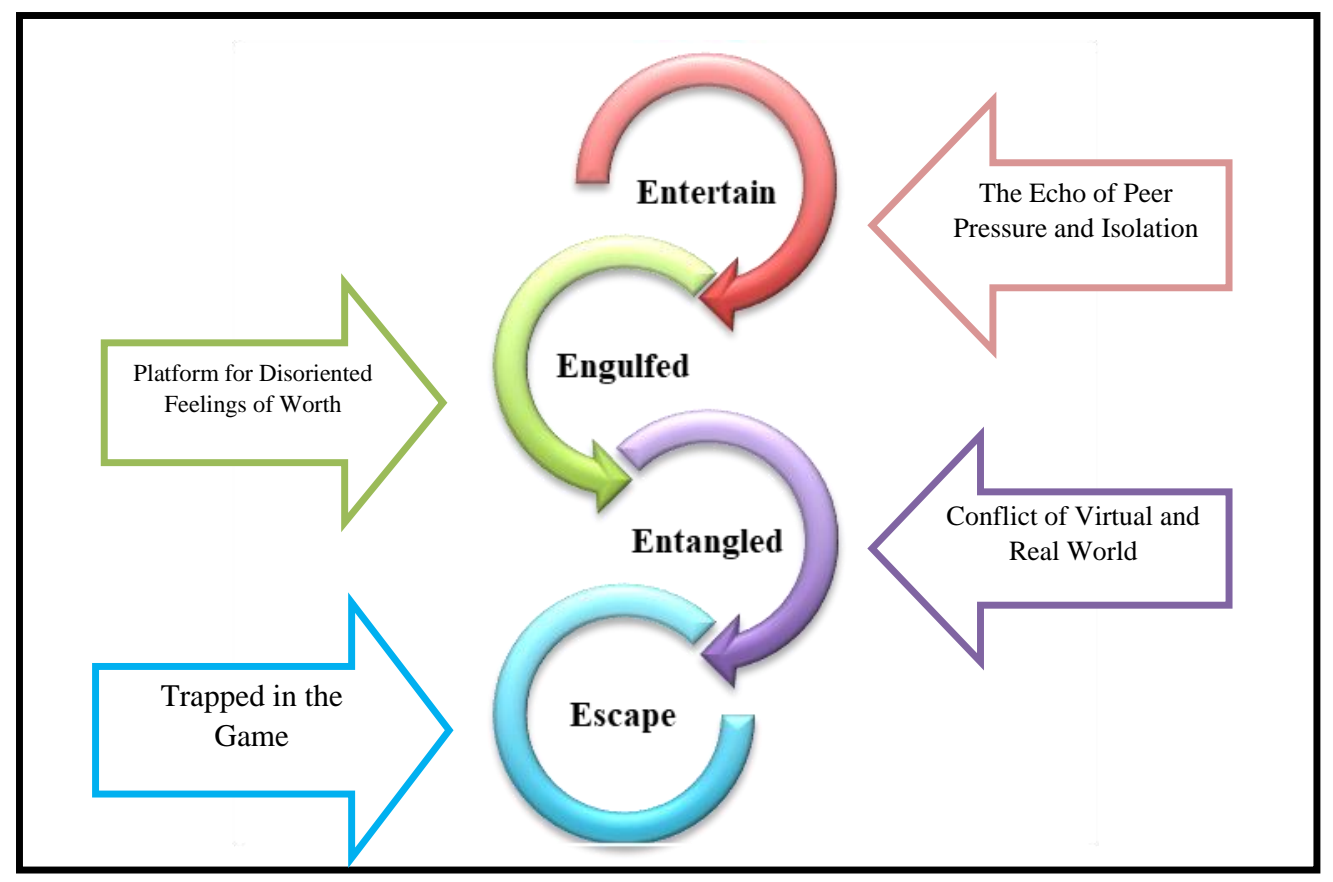

Figure 1: E-Loop of Internet Gaming Disorder Symptoms

\section{Entertain: The Echo of Peer Pressure and Isolation}

Driven by the flow of the internet and technological revolution, participants to go with the flow with the fear of being left out. Inspired by the pressures of the modern community, they resorted to advanced entertainment tools which can be readily available on their palms using the tip of their fingers. Also, the fear of being different from the group lead to excessive gaming behaviours. Hence, the echo of peer pressure has gone through the heads of the gamers and became habituated to it. Further, as games designed intentionally to be amusing, the experience of enjoyment to graphic fantasies, perfect figures and heroic characters resulted in gamers to engage in gaming excitingly, consuming most of their time. Mesmerized by high definition effects and flattery of the games, student gamers became hooked to different types of video games.

Surprisingly, the participants use the game entertainment features to isolate themselves from unwanted conversations with peers and family members. They use gaming to be distracted and avoid making social interactions, especially when they felt to be judged and discriminated by other people. Also, texts data revealed that the participants' lack of motivation in doing physical activities and other productive activities aside from gaming reinforce their gaming behaviour. Expensive recreations and sports activities have driven them to excessive to resort to online gaming which requires less efforts and believed to be less expensive.

As excerpted from the verbalizations of the participants: 
Table 2: Subthemes of the Echo of Peer Pressure and Isolation

\begin{tabular}{|c|c|}
\hline Subordinate Themes & Excerpts \\
\hline Peer pressure & $\begin{array}{l}\text { "It was the trend among my friends, and peers and I don't want to be left out." -P11 } \\
\text { "Teams and squads in ranks makes the games more exciting, and I'd always join my } \\
\text { friends online."-P32 }\end{array}$ \\
\hline Isolation & $\begin{array}{l}\text { "Gaming is my way to isolate myself from others, especially when I am aware that they } \\
\text { wouldn't want to talk to me or when I feel like they're judging me." -P14 } \\
\text { "At home, I chose to play mobile games to be alone and avoid interacting with my siblings } \\
\text { and parents, to avoid unpleasant discussions." -P10 }\end{array}$ \\
\hline Amusement & $\begin{array}{l}\text { "I find it amusing and entertaining, graphics, and heroes of different games were superb } \\
\text { and amazing." -P22 } \\
\text { "Being in the game is an amazing experience. The beautiful graphics, designs, and visual, } \\
\text { even audio effects were just amazing, making me feel like inside a fantasy world. It's just } \\
\text { entertaining."-P1 }\end{array}$ \\
\hline $\begin{array}{l}\text { Lack of motivation for } \\
\text { physical activities }\end{array}$ & $\begin{array}{l}\text { "I would rather be indoors and entertain myself with gaming than to go outside to play } \\
\text { sports activities. Sports activities like basketball can lead to physical injuries, cost you a lot } \\
\text { of money, and can create misunderstandings to the opponent teams." - P12 } \\
\text { "It is dangerous to stay outside nowadays; besides it could be very tiring and expensive. } \\
\text { I'd choose to stay at home, or in a corner happily play on my phone." P37 }\end{array}$ \\
\hline
\end{tabular}

\section{Engulfed: A Platform for Disoriented Feelings of Worth}

Started from being entertained, student gamers gradually become engulfed in gaming unconsciously. Being engulfed was due to the "achievements", "rewards", inapt praises, and recognition they receive thru gaming. Participants become deluded with the idea that they were accomplishing something significant and worthwhile. In this stage, the participants based their sense of fulfilment and successful endeavours that they have not experienced in the real physical world. Also, thru validations, it was found that their verbalizations also reflect the participants' lack of self-esteem and motivational drives to perform in a real-life setting.

Interestingly, I.G.D. symptoms stemmed from their perceived "sense of belongingness" and freedom to utter profane languages while gaming. The sense of liberty to express their feelings of violence and obscenity, without being reprimanded like in the physical world, is a huge contributing factor. The absence of physical contact became advantageous to gamers since they believe they can be more to be themselves without being judged. With the need to sustain their self-esteem and a sense of belongingness, the next curve in the loop arises. Also, immersed in video gaming, participants gained a sense of worth and satisfaction in ways of disoriented cognition, as they desired to be a real part of the virtual reality in video games.

As excerpted from the expressions of the participants:

Table 3: Subthemes of a Platform for Disoriented Feelings of Worth

\begin{tabular}{ll}
\hline Subordinate Themes & Excerpts \\
\hline sense of fulfilment & "There is that feeling of happiness, surreal that I can't explain when you reached high ranks \\
& or win matches. It is also inspiring when my fellow gamers compliment me as a great \\
& gamer. Especially when people I don't know, invite me to matches to help them pull their \\
& ranks, it just feels great."-P7 \\
& "It feels fulfilling when gamers praise you for a winning match, high ranks, many heroes, \\
& and achievements in the game. It gave some kind of positive feeling."-P31
\end{tabular}




\section{Entangled: The Conflict of Virtual and Real World}

Along the course of being engulfed in gaming, participants face a conflict between the virtual and the real physical world. Cognizant with disputes and failures in their real lives, they remain playing internet games as if their lives depends on it. Despite experiencing poor health and hygiene, a decline in academic performance decreased physical activities, and interpersonal conflicts with family and friends, participants continued to be 'passionate' in gaming. To the participants, gaming was not "just' a hobby, but a part of their lives and viewed it as a better activity than other vices.

Interestingly, participants also admitted because of problems that arise along with internet gaming tried to control their gaming activity, but most attempts were unsuccessful. Some of them experienced withdrawal symptoms. These problems caused participants' confusion and distress on becoming entwined with the opposite forces of the virtual and the physical world. Sadly, due to the dilemma, they experienced instead of mending broken relationships they would resort to internet gaming because, for them, it is a more accessible course of action.

As excerpted from the response of the participants:

Table 4: Subthemes of the Conflict of Virtual and Real World

\begin{tabular}{ll}
\hline $\begin{array}{l}\text { Subordinate } \\
\text { Themes }\end{array}$ & Excerpts \\
\hline $\begin{array}{l}\text { Unexplainable Game } \\
\text { Dependence }\end{array}$ & $\begin{array}{l}\text { "I know I have been playing too much, I was even in the dean's list before, but due to } \\
\text { absences and tardiness my grades gradually decreased." -P17 } \\
\text { "Playing mobile games had been my major activity, and for some reason, it is very } \\
\text { challenging to control as if my life depends on it." -P30 }\end{array}$
\end{tabular}

\begin{tabular}{|c|c|}
\hline $\begin{array}{l}\text { The perception of } \\
\text { "Good Gaming." }\end{array}$ & $\begin{array}{l}\text { "Playing caused me a long-time romantic relationship, but for me, there's nothing wrong. I } \\
\text { think being addicted to mobile gaming is better than being a drug addict. We broke up } \\
\text { because of her clinginess and selfishness." -P10 } \\
\text { "There are unhealthy things I did because of gaming like not eating properly, late or non- } \\
\text { submission of school requirements, being late or absent in school. But, I just can't stop } \\
\text { playing computer/mobile games. It is a part of my system." -P24 }\end{array}$ \\
\hline
\end{tabular}

Withdrawal "I tried to stop playing, I swear. There was once we went to the barrio, and I had no choice but to discontinue playing since there was no internet reception there. But during my stay, it was the only thing in my mind, and I even dreamt of it. When I couldn't take it, I went home to play. I didn't even take a bath. I can't just do it, I need to play, and it was hard to control." -P8

The easier course of "Maybe the worst case was it came to the point when I dropped out for a semester without action my parents' knowledge. I admit that it was mostly because of playing internet games and I can't explain how, sometimes you just don't notice the time, resulting in being late or absent, until I came to realize that the semester ended that way. I don't know. It's just that I feel elated, I feel different when in-gaming. It was like entering a whole new world where you can be somebody else, you are great, you can do what you want. Of course, I felt guilty about it, especially I am favored financially by my parents. But, what's done was done, and I can't turn back time, I cannot go back, that's why I played again to entertain myself rather than mind them and be wary. It is easier that way." -P13

\section{Escape: "Trapped in the Game"}

In this phase, participants had a brief realizations of the impairment caused by internet gaming. Most of them made actual efforts to reduce, control, or even eliminate internet gaming, but these attempts appeared to be unsuccessful. They exert individual efforts to escape the loop, a cycle of excessive gaming behaviour since they realized its adverse effects on their actual real life. However, due to the tremendous problematic results of extreme internet gaming, they found themselves going back to playing as a form of escape. Going back to their normal lives before gaming was perceived to be difficult, especially those who have lost significant relationships and opportunities. Additionally, when participants were engulfed and entangled with gaming for more than a year, they have developed an unhealthy physiological pattern of sleep and eating behaviours. Excessive gaming affected their "body-clock" and found themselves with sleepless nights and abnormal eating appetites which leads to frustrations, restlessness and irritability. Helpless to return wasted occasions and damaged interpersonal relationships with family and friends due to excessive time spent in gaming, they resorted to going back to gaming to "feel better" again. Hence, the patterns of behavior become a loop, repeatedly going back from the start leading to internet gaming disorder symptoms.

As excerpted from the narratives of experiences of the participants: 
Table 5: Subthemes of "Trapped in the Game"

\begin{tabular}{ll}
\hline Subordinate Themes & Excerpts \\
\hline Avoidance & "Uninstalling the game application, surrendering my phone to my friends, and even cutting \\
the Wi-Fi connection were the methods I used. I even throw myself in watching Korean \\
Series and MCU movies, which has the same result. I mean, I tried, I did try to control and \\
eliminate online and offline gaming. I want to go back, to win back people to go back \\
seriously with my studies but it doesn't work out."-P13 \\
"Honestly, I tried to put a halt in my gaming behaviour. I tried to go outside, see some \\
friends, reach out to my family, but there is no use." -P7 \\
\hline "Things just get annoying, and no matter where I looked and went, I see people playing \\
mobile games or computer games. That makes me think there is nothing wrong with it. \\
They just don't understand, it looks pretty normal to me, so I go back to gaming, it makes \\
me feel good."-P37 \\
"My body has been used to staying awake at night, making me feel sleepy and tired all day. \\
And besides, I couldn't relate with my friends anymore, it feels like I'm different, same \\
goes with my family. I couldn't go back since I can't remember how or when it started. I \\
have no choice but to go back to gaming, it is where I feel myself again."-P19 \\
"Every time I tried to control my gaming behaviour, I always find myself going back to it. \\
It feels like I'm running in circles, they get annoyed I will stop, when I stopped, it feels like \\
there's a missing part of me, so I go back again."-P1 \\
"It's just, I will stop playing one game then will discover something new, I will play \\
excessively again. Then, I am back to being scolded, abandoned and other negative things it \\
entails then, I'd exert effort to control. After a few days, I go back again, and I couldn't help \\
it because when I stopped gaming, it is not like everything will go back normal again. I've \\
lost people, I had bad grades, and it won't come back. So I cope with gaming again."-P24
\end{tabular}

\section{DISCUSSIONS}

As the students fought their way to "mythic" - the highest rank in the most popular online game, they became ultimately caught in a loop and was losing the road to reality. As the design of games is intended to be entertaining and addicting (Kuss et al., 2018), it stimulates the attention of today's generation (Gallup et al., 2016). Further, along with entertainment, the propensity of the participants to be inclined in gaming lies to a variety of factors such as isolation, distress, fear of being left out, and peer pressure. Similar to this, Saquib and his colleagues (2017) stressed the contribution of loneliness and psychological distress were risk factors to game addiction. Additionally, Rho et al. (2016) found that having game partners and the fear of being left-out were high risks factors for internet gaming disorder. According to Dong and Ponteza (2014), video games were like gamers' happy pill and made their mood in a pleasant state while gaming. Remarkably, the echoes of peer pressure and isolation played a vital role in the inception of excessive online gaming. Extreme internet gaming started when they were amused by high-tech graphics and systems. Students also used gaming to isolate themselves from the problems of the real world and embrace the entertaining virtual world. Exposure to the addictive design of gaming, they entered a loop where most gamers were confined.

Excessive exposure to the addictive design of online games leads to a vicious cycle resulting in the presence of Internet Gaming Disorder symptoms. Dong and Ponteza (2014) explained that "motivational drives linked to reward-seeking contribute importantly to I.G.D. and that diminished executive function/cognitive control over these motivational drives contribute to decision making that leads to a persistent engagement to internet game playing." Students with a lack of self-esteem and real-life achievement sought stress reduction activity to internet gaming. The motivations and rewards the students receive from internet gaming lead them to dysregulated gaming (Dong \& Ponteza, 2014). Experiencing reinforcements thru immersing in the virtual world amplified their internet gaming behaviour (Pontes et al., 2018). Gamers were hooked to internet gaming since it satisfied their cravings for recognition and self-esteem, as Wartberg et al. (2017) concluded that self-esteem problems were predictors of I.G.D.

As cited by King and Delfabbro (2019), "individuals with low self-esteem have less confidence, are prone to selfcriticism, and have difficulties in establishing and maintaining friendships". Hence, internet gaming satisfies the "emotional comfort" and provides an innocuous societal platform since online gaming includes asynchronistic social connection, secrecy and faceless interactions (Kowert et al., 2014). Researchers claimed that an individual have low selfesteem have a higher probability to engage in online gaming (Davis, 2001; King \& Delfabbro, 2014; Weis \& Cerankosky, 2010).

Games, particularly online gaming provided an avenue for gamers a useful way to some shy and socially withdrawn individuals to develop more social confidence, improve their mood and make "friends" online (Grohol, 2016; Tateno et al., 2016). Additionally, the sense of belongingness they felt and liberty to become profane and violent inside the internet gaming world served as another factor for them to more into it. Gallup et al. (2016) stated that these games provide unique opportunities to engage socially without risks and challenges of the face-to-face situation. Students can freely 
express their thoughts and create socially thru virtual bonds (Casey \& Evans, 2011). Gamers build alliances, virtual social interactions which can be beneficial in attaining goals of the quest, complete challenges and ultimate victories (Sakuma et al., 2017) which lead to the development of friendship and relationships which may extend beyond the virtual realm (Kuss, 2018). These virtual bonds make gamers more engaging in internet games which leads to I.G.D. Moreover, social experiences in the gaming-related forum in the online community by players who are grouped based on interests and preferences provide an avenue for affirmation and acceptance. Further, these games designed to amaze and stimulate gamers' curiosity to unending quest and missions lead to sleepless nights, declined school performance, losing contact to a physical, interpersonal relationship with families and eventually addictive behaviour.

The "entangled" stage emerges as a result of excessive day-to-day and an increasing amount of time allotted in gaming. Though gamers were gradually realizing the conflicts excessive internet gaming caused in their real lives, they continue to engage in gaming. Participants were experiencing severe physical, academic, and psychosocial problems due to excessive internet gaming. In this stage, they were too preoccupied with gaming, activity while missing out on important events and opportunities in their lives. Further, entangled with gaming they have experienced withdrawal symptoms and seemed to feel helpless to manage gaming activity. Persistent and recurrent use of the internet to engage in gaming lead to substantial distress to the gamers (A.P.A., 2013). Despite the clinically significant impairment, academic problems and psychosocial distress (Petry et al., 2014), players uncontrollably continue to engage in internet gaming (Bax, 2016). Furthermore, as stated by Kiraly, Griffiths and Demetrovics (2015) “...problematic gamers are unable to control their excessive gaming behaviour even after they realize the problems it causes their lives". As stated above, gamers usually fantasize about the game and experience withdrawal-like symptoms such as irritability, annoyance, restlessness and, or sadness. Counsellors working in the field identified similar struggles in clients such as cravings, withdrawal and tolerance (Day, 2017). Koo, Han, Park and Kwon (2017) found that gamers experienced a loss of control over their daily activities in addition to having difficulty in interpersonal relationships, academic performance and emotional and cognitive development. The occurrence of gaming disorder distinctly changes the priorities of gamers which leads to significantly reduced attention and ability to attend to vital non-gaming-related information, people and events. Gamers' uncontrollable behaviour lead to neglect in the importance of real-world aspects such as study, hygiene, sleep and physical interrelationships.

Manifestly, adverse outcomes of dysregulated gaming resulted in gamers' detachment and indifference from the physical world. Over a long time, they engaged in gaming, gamers' find it increasingly challenging to resume their involvement in real-world activities due to the weakening of physio-psycho-social skills. Van Rooij and Prause (2014) stressed that addiction exists when there a patient's efficacy to control their impulses is not present. King and Delfabbro (2019) mentioned that "a habitual pattern of gaming creates an expanding 'void' in the person's life, where progression in important life areas, such as school or career, becomes anchored to the time at which gaming has begun". Since it is difficult to resume to real-world, gamers tend to go back in gaming wherein they were caught on the "loop" continuously expanding the "void". Dysregulation (Weinstein et al., 2017) and lack of self-control (Rho et al., 2016) were the risk factors of problematic gaming. In this case, Filipino college student gamers were entangled experiencing a lack of selfcontrol. They also experience dysregulated gaming behaviour since it served as their source of freedom of expression, self-esteem and sense of belongingness. Escaping from the game to face their uncertain physical world caused by excessive internet gaming urged them to return to it as a form of escape. From this point, the gamers are on the loop of I.G.D., as they go back to gaming to be entertained again but this time, relieve their anxiety and frustration brought about most of gaming. Despite several attempts to control video gaming, gamers struggle to stop and continue to play (Wartberg et al., 2017), this is a form of escape from the problems they encounter in the real world (Day, 2017). Gamers tend to experience negative emotions or mood changes when they lose contact with gaming (King, Herd \& Delbarro, 2017). Gamers would instead choose to sit down and engage in the virtual world, then doing their previous hobbies and passion (Rho et al., 2017; Weinstein et al., 2017).

Notwithstanding the problems they faced and opportunities lost because of gaming, gamers would choose to play as if it is the only thing that matters. As mentioned by King et al. (2017), most problematic internet gamers started escaping from something unpleasant. Hence they ventured in engaging to the virtual world and eventually could not find ways out of it even if they wanted. Koo et al. (2017) explained that this phenomenon is due to psychological distress signals from cravings which activated and satisfied the brain's reward system when presented with video-gaming related signs.

Hence, the great loop amusement, being motivated to the game means coping in imperfections of their lives, and overvaluing games' resulted in I.G.D. symptoms. Escape to the unpleasant and unwanted real-life environment, lead internet gamers to maladaptive cognitions thru feelings of worth, esteem and belongingness to internet gaming honing of gaming skills and overvaluing gaming achievements. Gamers experience the "feeling of flow" or the immersive pleasure (Hu et al., 2018) to gaming which they were not able to attain in the actual reality.

\section{CONCLUSION}

The lived experiences of symptomatic college students reflect a never-ending loop of being entertained, engulfed, entangled, and escape. Their excessive time and energy spent in gaming resulted in an expanding vacuum leading them to more caught-up in the I.G.D. loop. Initially, gamers were engaged in gaming out of peer pressure and amazement to the features of the games. After participating, internet gamers hooked deeply with the rewards and achievements with the 
game's reinforcements and compliments resulting in them to increase the amount of time in gaming. Then, internet gamers faced tremendous physical, academic, psychosocial and interpersonal conflicts leading to psychological distress but found themselves trapped in gaming. And as they find ways to escape from gaming, they find themselves escaping the physical world for the entertaining virtual world.

Understanding this E-Loop of I.G.D. is essential to addressing the fast-growing number of student gamers, not only of college but the grade school as well. This study contributed to the limited in-depth analysis of internet gaming behaviour, especially in our country. Although gathered data in this study came from a few respondents, it can be supported actual observation among gamers around. The seriousness of psychosocial impairments brought by I.G.D. should not be undermined. Therefore, the richness of the results of this study can be a basis for intervention programs for different schools and universities in the country.

\section{LIMITATION AND STUDY FORWARD}

The conceptualized framework has been formulated thru in-depth analysis and validated. However, the nature of this psychological inquiry is only limited to the participation of the selected student gamers. For further research, replication using a quantitative method to check the reliability of formulated concepts.

\section{ACKNOWLEDGEMENT}

This work was supported by Commission on Higher Education (CHED) via CHED K to 12 Scholarship Program and polished by the valuable comments and suggestions of the pool of experts at the University of Santo Tomas (U.S.T.). Further, the researchers would like to express their gratitude to Dr. Rhowel Dellosa for valuable advice and motivation.

\section{CO-AUTHOR CONTRIBUTION}

The co-author served as the adviser and initial editor of this study. He contributed in the arrangement of themes emerged from the responses of the participants, and acted as the "critical friend" to validate the themes and subthemes to create the E-Loop of IGD.

\section{REFERENCES}

1. American Psychiatric Association. (2013). Diagnostic and statistical manual of mental disorders (5th ed.). Arlington, VA: American Psychiatric Publishing. https://doi.org/10.1176/appi.books.9780890425596

2. Bax, T. (2016). Internet gaming disorder in China: a biomedical sickness or sociological badness? SAGE Publication: Games and Culture, 11(3), 233-255. https://doi.org/10.1177/1555412014568188

3. Belanger-Lejars, V. O. (2015). Internet gaming and gambling disorder: a comparison of individual psychological factors. Journal of Psychology and Behavioral Science 3(2), 122-140. https://doi.org/10.15640/jpbs.v3n2a12

4. Billieux, J., Schimmenti, A., Khazaal, Y., Maurage, P. \& Heeren, A. (2015). "Are we psychopathologizing everyday life? A tenable blueprint of behavioural addiction research". Journal of Behavioral Addiction 4(3), 119-123. https://doi.org/10.1556/2006.4.2015.009

5. Cash, H., Rae, C. D., Steel, A. H., \& Winkler, A. (2012). Internet Addiction: A Brief Summary of Research and Practice. Current psychiatry reviews, 8(4), 292-298. https://doi.org/10.2174/157340012803520513

6. Casey, G \& Evans, T. (2011). Designing for learning: online social network as a classroom environment. International Review of Research in Open and Distance Learning 12(7), 16. https://doi.org/10.19173/irrodl.v12i7.1011

7. Castro, B. V. \& De Guzman, A. B. (2012). From scratch to notch: understanding private tutoring in the Philippines from the perspectives of cram school and formal administrators. Education and Urban Society 1(25), 221-245.

8. Day I. (2017). A family systems approach to the understanding and treatment of internet gaming disorder. SAGE Publication: The Family Journal: Counselling and Therapy for Couples and Families 25(3), 264-270. https://doi.org/10.1177/1066480717711108

9. Davis, R. A. (2001). A cognitive-behavioral model of pathological Internet use. Computers in Human Behavior, 17, 187-195. https://doi.org/10.1016/S0747-5632(00)00041-8

10. Deleuze, J., Long, J., Liu, T., Maurage, P. \& Billieux, J. (2018). Passion or addiction? Correlates of healthy versus problematic use of videogames in a sample of French-speaking regular players. Addictive Behaviors, 82 (1), 114-121. https://doi.org/10.1016/j.addbeh.2018.02.031

11. De Guzman, A.B., Hapan, M.F.Z. Understanding the Twists and Turns of Academic Deanship: A Phenomenology of Filipino Medical Technology Deans' Struggles as Organizational Managers. Asia-Pacific Edu Res 23, 261-272 (2014). https://doi.org/10.1007/s40299-013-0102-0

12. Dong, G. \& Ponteza, M. N. (2014). A cognitive-behavioural model of internet gaming disorder: theoretical underpinnings and clinical implications. Journal of Psychiatric Research 58, 7-11. https://doi.org/10.1016/j.jpsychires.2014.07.005

13. Entertainment Software Association - E.S.A. (2017). Essential facts about the computer and video gaming industry. https://www.theesa.com/wp-content/uploads/2019/03/ESA_EssentialFacts_2017.pdf 
14. Feng, W., Ramo, D. E., Chan, S. R., \& Bourgeois, J. A. (2017). Internet gaming disorder: Trends in prevalence 1998-2016. Addictive Behaviors, 75, 17-24. https://doi.org/10.1016/j.addbeh.2017.06.010

15. Gallup, J., Duff, C., Serianni, B. \& Gallup, A. (2016). An exploration of friendships and socialization for adolescents with autism engaged in massively multiplayer online role-playing games (MMORPG). Education and Training in Autism and Development Disabilities 51(3), 223-237. https://www.researchgate.net/publication/314502455

16. Gee, P. J. (2003). What video games have to teach us about learning and literacy? A.C.M. Computers in Entertainment 1(1). https://doi.org/10.1145/950566.950595

17. Grohol, J. M. (2016). Pokemon G.O. was reportedly helping people's mental health, depression. In Psych central. https://psychcentral.com/blog/pokemon-go-reportedly-helping-peoples-mental-health-depression

18. Hu, E., Stavropoulos, V, Anderson, A., Souri, M. \& Gallard, J. (2018). Internet gaming disorder: the feeling of flow of social games. Addictive Behaviors Reports 10(4), 1-8. https://doi.org/10.1016/j.abrep.2018.10.004

19. Kamenez, N. V. (2020). Information Technologies as a means of assessing the knowledge of students of the technical profile. Journal of Critical Reviews, 7 (1), 348-350. https://doi.org/10.31838/jcr.07.01.70

20. Kardefelt-Winther, D. (2014). Problematizing excessive online gaming and its psychological predictors. Computers in Human Behavior, 31, 118-122. https://doi.org/10.1016/j.chb.2013.10.017

21. Kardefelt-Winther, D. (2017), Conceptualizing Internet-use disorders: Addiction or coping process? Psychiatry Clin. Neurosci., 71: 459-466. https://doi.org/10.1111/pcn.12413

22. King, D. L. \& Delfabbro, P. H. (2019). "Internet gaming disorder: theory, assessment and treatment $1^{\text {st }}$ edition. Academic Press Elsevier. https://doi.org/10.1016/B978-0-12-812924-1.09986-X

23. King, D. L. \& Delfabbro, P. H. (2014). The cognitive psychology of Internet gaming disorder. Clinical Psychology Review 34, 298-308. https://doi.org/10.1016/j.cpr.2014.03.006

24. King, D. L., Herd, M. C. \& Delfabbro, P. H. (2017). Tolerance in internet gaming disorder: a need for increasing gaming time or something else? Journal of Behavioral Addictions 6(4), 1-9 https://doi.org/10.1556/2006.6.2017.072

25. Király, O., Griffiths, M. d. \& Demotrovics, Z. (2015). Internet gaming disorder and the DSM-5: conceptualization, debates and controversies. Current Addiction Research 2, 254-262. https://doi.org/10.1007/s40429-015-0066-7

26. Koo, H. J., Han, D. H., Park, S. Y. \& Kwon, J. H. (2017). The Structured Clinical Interview for DSM-5 Internet Gaming Disorder: Development and Validation for Diagnosing I.G.D. in Adolescents. Psychiatry Investigation, 14(1), 21-29. https://doi.org/10.4306/pi.2017.14.1.21

27. Kosheleva, A., Atamuxamedov, A. \& Sabirova, S. (2020). Game as an activity in culture and pedagogy of Uzbekistan. Journal of Critical Reviews 7.4 (2020), 416-420. https://doi.org/10.31838/jcr.07.04.80

28. Kowert, R., Domahidi, E., Festl, R., \& Quandt, T. (2014). Social gaming, lonely life? The impact of digital game play on adolescents' social circles. Computers in Human Behaviour, 36, 385390. https://doi.org/10.1016/j.chb.2014.04.003

29. Kuss, D. J., Pontes, H., Király, O. \& Demetrovics, Z. (2018). A Psychological Overview of Gaming Disorder. The Oxford Handbook of Cyberpsychology, 1-23. https://doi.org/10.1093/oxfordhb/9780198812746.013.25

30. Lemmens, J. S., Valkenburg, P. M. \& Gentile, D. A. (2015). The internet gaming disorder scale. Psychological Assessment. Advance online publication. https://doi.org/10.1037/pas0000062

31. Mills D.J. \& Allen J.J. (2019). Self-determination theory, internet gaming disorder, and the mediating role of self-control, Computers in Human Behavior. https://doi.org/10.1016/j.chb.2019.106209

32. Morrow, R., Rodriguez, A. and King, N. (2015). Colaizzi's descriptive phenomenological method. The Psychologist, 28(8), 643-644. http://eprints.hud.ac.uk/26984/

33. Moudiab, S. \& Spada, M. M. (2019). The relative contribution of motives and maladaptive cognitions to levels of Internet Gaming Disorder. Addictive Behaviors Reports 9, Elsevier. 100160. https://doi.org/10.1016/j.abrep.2019.100160

34. Petry, N. M., Rehbein, F., Gentile, D. A., Lemmens, J. S., Rumf, H. J., Moßle, T., Bischof, G., Tao, R., Fung, D. S., Borges, G., Auriacombe, M., Gonzales, Ibanez, A., Tam, P. \& O’brien, C. P. (2014). An international consensus of assessing internet gaming disorder using the new DSM-5 approach. Addiction, 109 (9). 13991406. https://doi.org/10.1111/add.12457

35. Petry, N. M., Rehbein, F., Ko, C. H. et al. (2015) Internet gaming disorder in the DSM-5. Current Psychiatry Reports 17: 72. https://doi.org/10.1007/s11920-015-0610-0

36. Pontes, H.M., Schivinski, B., Sindermann, C., Mei, L., Becker, B., Zhou, M. \& Montag, C. (2019). Measurement and Conceptualization of Gaming Disorder According to the World Health Organization Framework: the Development of the Gaming Disorder Test. Int $J$ Ment Health Addiction. https://doi.org/10.1007/s11469-019-00088-Z

37. Pontes, H. M. (2016). Current practices in the clinical and psychometric assessment of internet gaming disorder in the era of the DSM-5: a mini-review of existing assessment tools. Mental Health and Addiction Research 1(1). https://doi.org/10.15761/MHAR.1000105 
38. Pontes, H. M. and Griffiths, M. D. (2015). Measuring DSM-5 internet gaming disorder: Development and validation of a short psychometric scale. Computers in Human Behavior 45 (2015) 137-143. https://doi.org/10.1016/j.chb.2014.12.006

39. Rahmadi L. \& Prambayun, A. (2019). Design of Game Design Document as an Interactive Media to Introduce the Culture of Pagar Alam City. Journal of Critical Reviews, 6 (5), 243-251.

40. Rho, M. J., Lee, H., Lee, T., Cho, H., Jung, D., Kim, D. \& Choi, Y. (2017). Risk factors for internet gaming disorder: psychological factors and internet gaming characteristics. International Journal of Environmental Research and Public Health 15, 40. https://doi.org/10.3390/ijerph15010040

41. Rosyati, T., Purwanto, M., Gumelar, G., Yulianti, R., \& Mukharrom, T. (2020). Effects of Games and How Parents Overcome Addiction to Children. Journal of Critical Reviews 7(1), 65-67.

42. Sakuma, H., Satoko, M., Nakayama, H., Kitayuguchi, T., Maezono, M. Hashimoto, T. \& Higuchi, S. (2017). Treatment with the self-discovery camp (S.D.C.) improved gaming disorder. Addictive Behaviors 64, 357-362. https://doi.org/10.1016/j.addbeh.2016.06.013

43. Saquib, N., Saquib, J., Wahid, A., Ahmed, A. A., Dhuhayr, H., Zaghloul, M. \& Ewid, M. (2017). Video game addiction and psychological distress among expatriate adolescent in Saudi Arabia. Addictive Behavior Reports, Elsevier 6, 112-117. https://doi.org/10.1016/j.abrep.2017.09.003

44. Scharkow, M., Festl, R. and Quandt, T. (2014), Longitudinal patterns of problematic gaming. Addiction, 109: 1910-1917. https://doi.org/10.1111/add.12662

45. Snyder, M. (2018). China digital game sector. US-China Economic and Security Review Commission. https://www.uscc.gov/files/000772

46. Suriya, A(2019). Psychology factor-based sentiment analysis for online product customer review using multimixed short text ridge analysis. Journal of Critical Reviews, 6(6) , 146-150.

47. Tateno, M., Skokauskas, N., Kato, T. A., Teo, A. R., \& Guerrero, A. (2016). New game software (Pokémon Go) may help youth with severe social withdrawal, hikikomori. Psychiatry Research, 246, 848-849. https://doi.org/10.1016/j.psychres.2016.10.038

48. Van Rooij, A. J., \& Prause, N. (2014). A critical review of "Internet addiction" criteria with suggestions for the future. Journal of behavioral addictions, 3(4), 203-213. https://doi.org/10.1556/JBA.3.2014.4.1

49. Wartberg, L., Kriston, L., Zieglmeier, M., Lincoln, T., \& Kammerl, R. (2018). A longitudinal study on psychosocial causes and consequences of Internet gaming disorder in adolescence. Psychological Medicine, 49(2), 287-294. https://doi.org/10.1017/S003329171800082X

50. Wartberg, L., Kriston, L., Zieglmeier, M., Lincoln, T., \& Kammerl, R. (2017). Internet gaming disorder in early adolescence: associations with parental and adolescent mental health. European Psychiatry 43, 14-18. https://doi.org/10.1016/j.eurpsy.2016.12.013

51. Weinstein, N., Pryzybylski, A. \& Murayama, K. (2017). A prospective study of the motivational and health dynamics of internet gaming disorder. PeerJ 5 (e3838). https://doi.org/10.7717/peerj.3838

52. Weis, R., \& Cerankosky, B. C. (2010). Effects of video-game ownership on young boys' academic and behavioral functioning: a randomized, controlled study. Psychological Science, 21, 463-470. https://doi.org/10.1177/0956797610362670

53. World Health Organization (2018). Video Gaming Disorder. https://www.who.int/news-room/q-adetail/gaming-disorder 